\title{
Probability of Galvanic Corrosion of Cr-bearing Rebars in Concrete
}

\author{
Sung-Ho TAE \\ School of Architecture \& Architectural Engineering, Hanyang University, 1271 Sa 3-dong, Sangrok-gu Ansan, Korea. \\ E-mail: jnb55@hanyang.ac.kr
}

(Received on November 21, 2008; accepted on March 24, 2009)

\begin{abstract}
Chloride-laden and carbonated environments were selected for the investigation of corrosion acceleration due to galvanic corrosion of normal rebars in contact with corrosion-resistant Cr-bearing rebars embedded in concrete. Concrete specimens simulating these environments were fabricated using normal steel (SD345) rebars in contact with Cr-bearing rebars and subjected to corrosion-accelerating curing with high temperature/high humidity and low temperature/low humidity cycles. The half-cell potential, corrosion area, and corrosion loss of the normal steel rebars were measured at the specified test ages.

No corrosion acceleration due to galvanic corrosion was observed on SD345 rebars in contact with Crbearing rebars in chloride-laden and carbonated concretes, suggesting the possibility of the selective use of Cr-bearing rebars for newly built structures only where necessary and their use as a repair material for patching.

KEY WORDS: Cr-bearing rebar; galvanic corrosion; chloride-laden environment; carbonated environment.
\end{abstract}

\section{Introduction}

Corrosion concentrates on certain points of steel reinforcement when there are macroscopic dissimilarities in concrete or steel surfaces. Investigation into macroscopic corrodibility is vital for the durability assessment of reinforced concrete, as the rate of macrocell corrosion is higher than that of microcell corrosion and the resulting penetration tends to be detrimentally deep for a small corrosion area. $^{1-3)}$ Such a macrocell corrosion phenomenon takes various forms depending on the corrosive environment, and galvanic corrosion is a typical kind of macrocell corrosion. When dissimilar metals are in contact, the metals are separated into the anode with a less noble corrosion potential and the cathode with a more noble corrosion potential, causing galvanic corrosion of the anode. Moreover, its propagation rate, which is higher than a normal microcell corrosion rate, can increase as the potential difference between the two metals increases and as the area ratio of the anode to cathode $(\mathrm{A} / \mathrm{C})$ decreases. Galvanic corrosion is therefore critical in the assessment of the durability of concrete. $^{4-6)}$

Meanwhile, a large number of studies have been conducted on the improvement of concrete with the aim of inhibiting reinforcing steel corrosion amid the demand for long service life of reinforced concrete structures over 100 years, but the improvement of concrete is not sufficient or realistic. $^{7-9)}$ Research into corrosion-resistant rebars has therefore been anticipated. Nevertheless, despite their excellent corrosion resistance, conventional corrosion-resistant rebars have not been generally adopted for actual con- struction. This is because of the high cost due to the addition of expensive alloy elements such as chromium, nickel, and molybdenum and the necessity for extra processes in addition to the production of normal steel. ${ }^{10-13)}$ A combination of corrosion-resistant rebars and normal rebars has therefore been proposed for better efficiency in the use of corrosion-resistant rebars. This is to apply corrosion-resistant rebars only to critical segments requiring corrosion resistance, such as those exposed to outdoor air and those in splash zones. However, as stated above, connecting corrosion-resistant rebars and normal rebars having different corrosion potentials may cause galvanic corrosion of less noble normal steel, conversely accelerating corrosion.

With this as a background, the authors have conducted studies on the corrosion resistance of Cr-bearing corrosionresistant rebars under various corrosive environments with the aim of developing commercially feasible Cr-bearing corrosion-resistant rebars (hereafter referred to as Cr-bearing rebars). ${ }^{14-17)}$ These rebars contain reduced alloy elements to enable their production by the same processes as normal steel rebars while retaining the required durability. Among the many studies conducted by the authors on $\mathrm{Cr}$ bearing rebars, this study investigated corrosion of normal rebars in contact with Cr-bearing rebars accelerated by galvanic corrosion, so as to develop Cr-bearing rebars suitable for different corrosive environments. For this purpose, chloride-laden environments and carbonated environments were selected as the corrosive environments. Concrete specimens simulating these environments were fabricated and subjected to corrosion-accelerating curing involving repeated high and low temperatures as well as moistening and dry- 
ing. The half-cell potential, corrosion area, and corrosion loss of normal rebars in contact with $\mathrm{Cr}$-bearing rebars were measured at the specified test ages.

\section{Outline of Experiment}

In this study, concrete specimens simulating chlorideladen and carbonated environments were fabricated to investigate the accelerated corrosion of normal rebars in contact with Cr-bearing rebars by galvanic corrosion in these corrosive environments. These specimens are referred to as chloride attack specimens and carbonation specimens in this study. Ten levels of rebars including SD345 standard rebars conforming to JIS G 3112, eight types of Cr-bearing rebars, and SUS 304 stainless steel rebars were tested. Each bar was tied crosswise with two SD345 rebars, which were $80 \mathrm{~mm}$ apart from each other, using binding wire as shown in Fig. 1 to induce galvanic corrosion of SD345 bars due to contact with Cr-bearing or SUS304 rebars. The cathodic and anodic bars were $13 \mathrm{~mm}$ and $9 \mathrm{~mm}$ in diameter, respectively, with the oxide film having been removed. Both chloride attack and carbonation specimens were demolded after seal curing up to an age of $7 \mathrm{~d}$. When producing concrete for chloride attack specimens, water containing chloride ions was used as mixing water so that the resulting concrete would contain $1.2 \mathrm{~kg}$ of chloride ions per cubic meter. Chloride attack specimens were then air-cured under thermo-hygrostatic conditions at $20 \pm 3^{\circ} \mathrm{C}$ and $50 \pm 5 \%$ R.H. for a week and subjected to rebar corrosion-accelerating cycles, with each cycle consisting of a high-temperature and high-humidity phase at $60^{\circ} \mathrm{C}$ and $95 \%$ R.H. for $1 \mathrm{~d}$ and a low-temperature and low-humidity phase at $30^{\circ} \mathrm{C}$ and $50 \%$ R.H. for $1 \mathrm{~d}$. The half-cell potential of SD345 bars in contact with various rebars was measured up to 115 cycles, while the corrosion area and corrosion loss were measured at 40,70 , and 115 cycles to investigate corrosion acceleration of SD345 in contact with Cr-bearing rebars by galvanic corrosion.

Carbonation specimens were air-cured in a thermo-hygrostatic room at $20 \pm 3^{\circ} \mathrm{C}$ and $50 \pm 5 \%$ R.H. for a month after preliminary curing for $7 \mathrm{~d}$. These were then subjected to accelerated carbonation curing so that carbonation would proceed from the surfaces to the backside of the cathodic bars. This was followed by corrosion-accelerating cycles, with each cycle consisting of a high-temperature and highhumidity phase at $60^{\circ} \mathrm{C}$ and $95 \%$ R.H. for $1 \mathrm{~d}$ and a lowtemperature and low-humidity phase at $30^{\circ} \mathrm{C}$ and $50 \%$ R.H. for $1 \mathrm{~d}$. The half-cell potential of SD345 bars was measured up to 135 cycles, while the corrosion area and corrosion loss were measured at 45, 90, and 135 cycles. The four

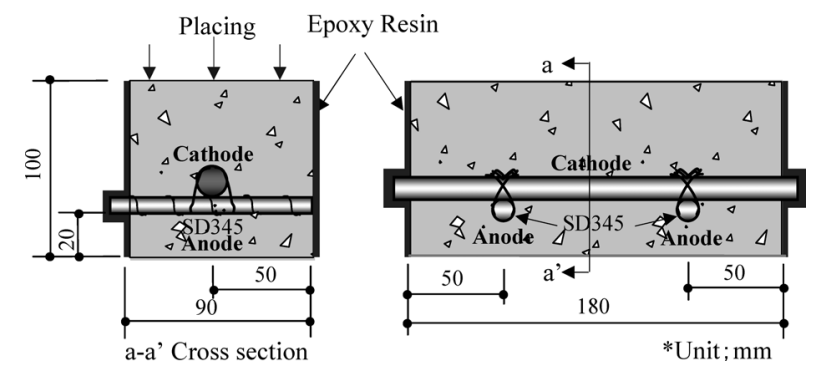

Fig. 1. Details of test specimen. sides excepting the top and bottom surfaces in the concrete placing position of both chloride attack specimens and carbonation specimens were sealed with epoxy. Tables $\mathbf{1}$ and $\mathbf{2}$ give the basic compositions of rebars and concrete mixture proportions, respectively.

\section{Test Procedures}

\subsection{Half-cell Potential}

Time-related changes in the half-cell potential of SD345 bars $9 \mathrm{~mm}$ in diameter, which were embedded in chloride attack specimens and carbonation specimens to be the anodes, were measured up to 115 and 135 cycles, respectively, of corrosion-accelerating curing. A saturated copper-copper sulfate electrode (CSE) was used as the reference electrode. Specimens were immersed in water for one day from the previous day of the measurement to adjust their moisture conditions.

\subsection{Carbonation-accelerating Curing}

Carbonation-accelerating curing was conducted so that carbonation beginning from the surfaces would reach the backside of the cathodic bar as shown in Fig. 2. The carbonation accelerating conditions were a temperature of $40^{\circ} \mathrm{C}$, relative humidity of $60 \%$, and $\mathrm{CO}_{2}$ concentration

Table 1. Material properties.

\begin{tabular}{|l|l|l|l|l|l|l|l|l|}
\hline Steel & $\mathrm{C}$ & $\mathrm{Si}$ & $\mathrm{Mn}$ & $\mathrm{P}$ & $\mathrm{S}$ & $\mathrm{Cr}$ & $\mathrm{Ni}$ & $\mathrm{Mo}$ \\
\hline SD345 & 0.2190 & 0.300 & 1.34 & 0.035 & 0.019 & 0.081 & 0.04 & 0.01 \\
\hline $3 \mathrm{Cr}$ & 0.0106 & 0.305 & 0.52 & 0.033 & 0.006 & 3.070 & 0 & 0 \\
\hline $5 \mathrm{Cr}$ & 0.0112 & 0.260 & 0.52 & 0.030 & 0.005 & 4.880 & 0 & 0 \\
\hline $7 \mathrm{Cr}$ & 0.0105 & 0.270 & 0.53 & 0.031 & 0.005 & 7.150 & 0 & 0 \\
\hline $9 \mathrm{Cr}$ & 0.0114 & 0.270 & 0.52 & 0.029 & 0.005 & 9.070 & 0 & 0 \\
\hline $11 \mathrm{Cr}$ & 0.0098 & 0.276 & 0.52 & 0.030 & 0.005 & 11.110 & 0 & 0 \\
\hline $13 \mathrm{Cr}$ & 0.0108 & 0.270 & 0.51 & 0.029 & 0.006 & 12.900 & 0 & 0 \\
\hline $16 \mathrm{Cr}$ & 0.0094 & 0.270 & 0.53 & 0.030 & 0.005 & 16.090 & 0 & 0 \\
\hline SUS304 & 0.0620 & 0.297 & 1.02 & 0.030 & 0.006 & 18.280 & 8.15 & 0.05 \\
\hline
\end{tabular}

Table 2. Mixture compositions of concrete.

\begin{tabular}{|c|c|c|c|c|c|c|c|}
\hline \multirow{2}{*}{ Environment } & \multirow{2}{*}{$\begin{array}{c}\mathrm{Cl}^{-} \\
\left(\mathrm{kg} / \mathrm{m}^{3}\right)\end{array}$} & $\begin{array}{c}\text { Water/ } \\
\text { Cement ratio } \\
(\%)\end{array}$ & $\mathrm{S} / \mathrm{A}^{*}$ & \multicolumn{4}{|c|}{ Unit weight $\left(\mathrm{kg} / \mathrm{m}^{3}\right)$} \\
\cline { 5 - 8 } & & & Water & Cement & $\begin{array}{c}\text { Fine } \\
\text { aggregate }\end{array}$ & $\begin{array}{c}\text { Coarse } \\
\text { aggregate }\end{array}$ \\
\hline Chloride-laden & 1.2 & 60 & 46 & 185 & 285 & 798 & 954 \\
\hline Carbonated & 0 & & & & & & \\
\hline
\end{tabular}

"Sand(Fine aggregate) to Aggregate(Fine aggregate + Coarse aggregate) ratio

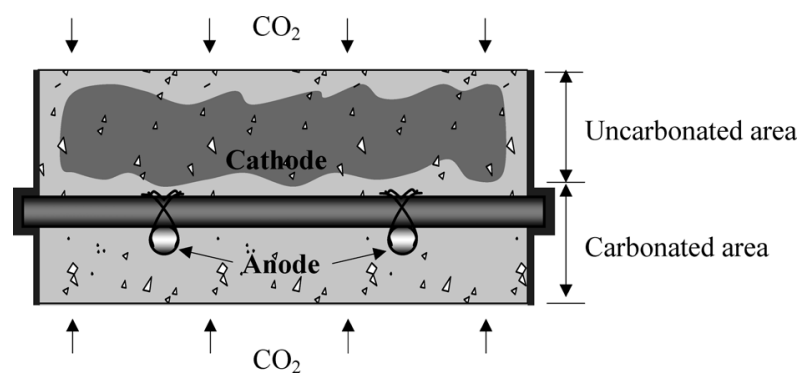

Fig. 2. Carbonation area. 

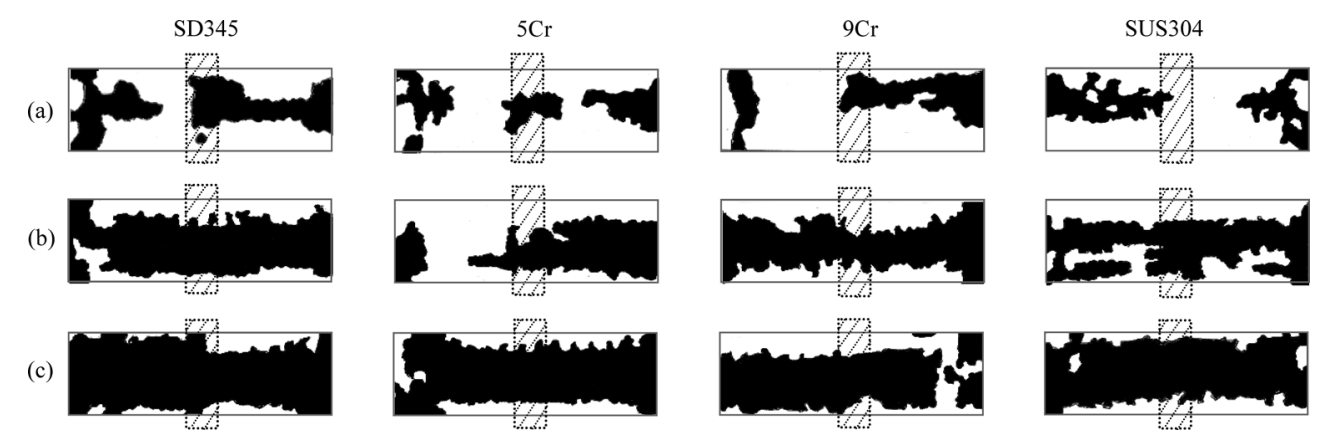

Fig. 3. Typical states of corrosion of SD 345 in contact with SD345, 5Cr, $9 \mathrm{Cr}$, and SUS304.

of $5 \%$. Specimens for measuring the carbonation depth were cleft for spraying a $1 \%$ alcoholic solution of phenolphthalein on the exposed surfaces, and the uncolored areas were judged as being carbonated.

\subsection{Corrosion Area and Corrosion Loss}

The corrosion area and corrosion loss of anodic SD345 bars $9 \mathrm{~mm}$ in diameter embedded in chloride attack specimens and carbonation specimens were measured. These bars were chipped out of chloride attack specimens at the end of 40,70, or 115 cycles and carbonation specimens at the end of 45, 90, or 135 cycles of corrosion-accelerating curing. Rust areas on each bar were then traced on a transparent sheet and blacked out to calculate the corrosion area using automatic planimetric software. SD345, 0Cr, and $5 \mathrm{Cr}$ bars among the recovered bars were derusted with a $10 \%$ aqueous solution of diammonium hydrogen citrate, whereas bars with a $\mathrm{Cr}$ content exceeding $5 \%$ were derusted with a $15 \%$ aqueous solution of nitric acid. Their mass was then measured to $0.01 \mathrm{~g}$ using an electronic balance, and the corrosion loss was determined using Eq. (1). ${ }^{18)}$

$$
\Delta W=\frac{\left(W_{0}-W\right)-W_{\mathrm{s}}}{W_{0}} \times 100
$$

Where $\Delta W$ is weight loss (\%), $W_{0}$ is initial rebar mass $(\mathrm{g}), W$ is rebar mass after rust removal $(\mathrm{g}), W_{\mathrm{s}}$ is amount of uncorroded part dissolved (g) (separately measured).

\section{Test Results and Discussion}

\subsection{Test Results of Chloride Attack Specimens \\ (1) Corrosion Patterns}

Figure 3 shows typical states of corrosion of SD345 in contact with SD345, 5Cr, 9Cr, and SUS304. These were obtained by tracing the rust areas on each bar through a transparent sheet at the end of 40,70 , or 115 cycles of corrosion-accelerating curing and blacking out these areas. The hatched areas in the figure represent the areas in contact with different metals. Figure 3 reveals that the corrosion of SD345 in contact with SD345 at the end of 40 cycles does not particularly concentrate on the contact area, propagating over the surface as the number of cycles increases to 70 and to 115 in uniform patterns. This phenomenon is similarly observed on SD345 bars in contact with $5 \mathrm{Cr}$, 9Cr, and SUS304 bars containing $\mathrm{Cr}$, showing no marked concentration of corrosion at contact areas with different metals.

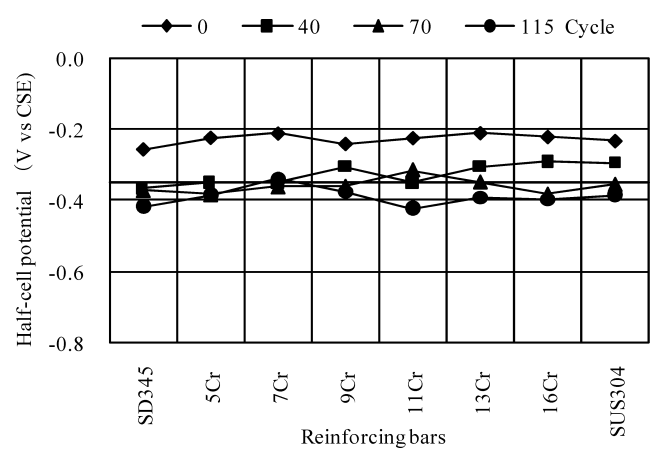

Fig. 4. Half-cell potential of SD345 in contact with various types of rebars [chloride-laden environment].

\section{(2) Half-cell Potential}

Figure 4 shows the half-cell potential of SD345 in contact with various types of rebars. The half-cell potential values are those of SD345 in contact with the indicated metals. The horizontal bold line in the figure indicates a half-cell potential value of $-0.35 \mathrm{~V}$ ( $v s$. CSE), which is regarded as a $90 \%$ possibility of corrosion by the judgment criterion for corrosion specified in ASTM C 876-80. According to Fig. 4, the half-cell potential becomes more negative as the corrosion-accelerating curing proceeds, being close to $-0.35 \mathrm{~V}$ at 40 cycles and later regardless of the steel type. When comparing bar types at the same age, the half-cell potentials of SD345 bars in contact with bars containing $\mathrm{Cr}$ and SUS 304 bars are slightly less negative than those of SD345 bars in contact with SD345. In other words, the half-cell potentials of SD345 in contact with bars containing $\mathrm{Cr}$ do not tend to be more negative than those of SD345 in contact with SD345.

\section{(3) Corrosion Area}

Figure 5 shows the time-related changes in the corrosion area of SD345 in contact with bars containing $\mathrm{Cr}$ in concrete with a chloride ion content of $1.2 \mathrm{~kg} / \mathrm{m}^{3}$. The corrosion area of SD345 bars increases as the corrosion-accelerating curing proceeds regardless of the steel type in contact. Also, the corrosion areas of SD345 bars in contact with bars containing $\mathrm{Cr}$ are smaller than those of SD345 bars in contact with SD345 bars at all ages under the same corrosion-accelerating conditions. The corrosion area of SD345 is smallest in contact with $3 \mathrm{Cr}$ with a $\mathrm{Cr}$ content of $3 \%$ and tends to increase as the $\mathrm{Cr}$ content increases. However, even when in contact with SUS304, a stainless steel, the corrosion area of SD345 is smaller than that of SD345 in contact 


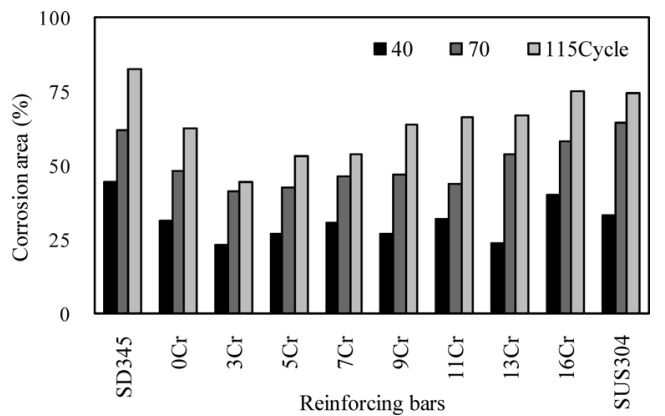

Fig. 5. Corrosion area of SD345 in contact with various types of rebars [chloride-laden environment].

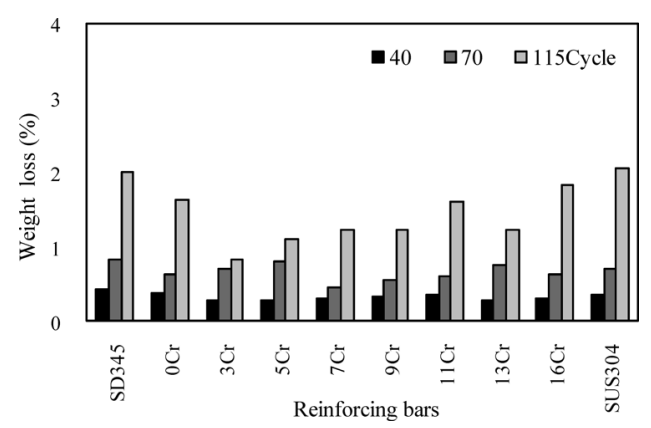

Fig. 6. Corrosion loss of SD345 in contact with various types of rebars [chloride-laden environment]

with SD345.

\section{(4) Corrosion Loss}

Figure 6 shows the time-related changes in the corrosion loss of SD345 in contact with bars containing $\mathrm{Cr}$ in concrete with a chloride ion content of $1.2 \mathrm{~kg} / \mathrm{m}^{3}$. Similarly to the results of corrosion area measurement, the corrosion loss of SD345 increases as the Cr content increases regardless of the bar type. Also, the corrosion loss of SD345 is smallest when in contact with $3 \mathrm{Cr}$ and tends to increase as the $\mathrm{Cr}$ content increases. However, even when in contact with SUS304, the corrosion loss of SD345 is smaller than that of SD 345 in contact with SD345.

These results reveal that, when SD345 comes into contact with Cr-bearing rebars in concrete containing chlorides, corrosion is not accelerated by galvanic corrosion but rather retarded. When different metals are used in combination, the corrosion rate of the anodic base metal is affected by the difference between the reference single electrode potentials of the anodic and cathodic metals and their surface area ratio. In other words, the corrosion rate of the anodic base metal normally increases as the difference between the reference single electrode potentials of both metals increases and as the surface area ratio of the anodic metal to the cathodic metal decreases. On the other hand, according to the literature on the galvanic corrosion of normal steel in contact with stainless steel, normal steel and stainless steel in contact with each other in concrete are experimentally and theoretically found to cause no galvanic corrosion of normal steel. This is explained as follows: When normal steel is in contact with stainless steel, the corrosion current flowing from normal steel to stainless steel is relatively small, as the cathodic current of stainless steel is marginal. It has therefore been pointed out that the effect of galvanic

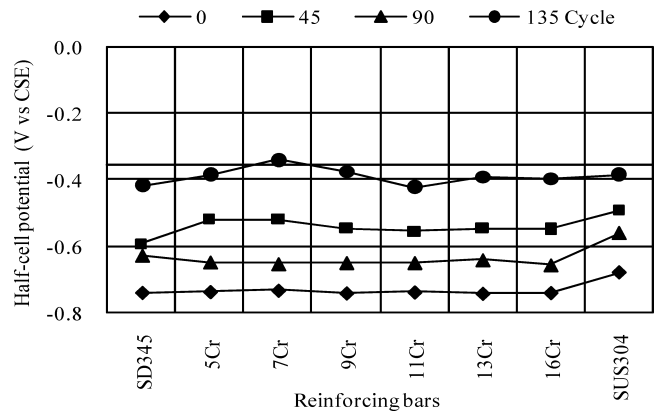

Fig. 7. Half-cell potential of SD345 in contact with various types of rebars [carbonation environment].

corrosion can be weaker than the case of normal steel in contact with the same normal steel. ${ }^{19-21)}$ In this light, the results with Cr-bearing rebars used in the present tests may be similarly explained.

Accordingly, the results of tests for half-cell potential, corrosion area, and corrosion loss in this study show that the use of Cr-bearing steel in combination with normal steel does not accelerate corrosion by galvanic corrosion in a corrosive environment prone to chloride attack. Cr-bearing steel can therefore be used selectively for newly constructed structures only where necessary and as a repair material for patching.

\subsection{Test Results of Carbonation Specimens \\ (1) Corrosion Patterns}

The corrosion patterns of SD345 bars in contact with Crbearing rebars in carbonated concrete were similar to those in a chloride-laden environment stated above, showing no intensive corrosion at areas of SD345 in contact with different metals. Also, as is evident from the results of the corrosion area, no large corrosion was observed on SD345 bars in contact with Cr-bearing bars when compared with those in contact with SD345 bars.

\section{(2) Half-cell Potential}

Figure 7 shows the half-cell potential of SD345 in contact with various metals in carbonated concrete. The bold line in the graph represents a potential of $-0.35 \mathrm{~V}$ ( $v s$. CSE), the corrosion assessment criterion specified by ASTM C 876-80. However, the criterion value of ASTM C 876 is not necessarily applicable to concrete structures in all environments, as it primarily addresses structures prone to chloride attack, such as bridge decks. ${ }^{22)}$ Moreover, a new assessment criterion is considered necessary for corrosion of Cr-bearing rebars, as the anodic polarization curve of rebars containing $\mathrm{Cr}$ differs from that of carbon steel. ${ }^{23)}$ The authors' previous research has revealed that the assessment criterion by ASTM C 876 is applicable to a certain extent in a chloride-laden environment as a judgment criterion for corrosion of steel with any $\mathrm{Cr}$ content. ${ }^{24)}$ However, a new assessment criterion is deemed necessary for judging corrosion of Cr-bearing rebars in the carbonation environment in this section. Nevertheless, careful judgment based on numerous research data and data accumulation from a wider range are necessary for establishing such a new assessment criterion. In consideration of this situation, the authors employ in this section the half-cell potential of steel as the ref- 
erence values for comparison instead of the assessment criterion for corrosion onset specified in ASTM C 876. Figure 7 reveals that the half-cell potential tends to become less negative as corrosion acceleration curing proceeds regardless of the steel type, presumably because the inside of specimens progressively dries over time in the corrosionaccelerating environment, increasing the electrical resistance in concrete. Also, the half-cell potential of SD345 bars in contact with Cr-bearing bars is nearly the same as that of SD345 bars in contact with SD345 bars throughout the period of corrosion-accelerating curing, the former being scarcely more negative than the latter in the carbonation environment similarly to the results of half-cell potential tests in the chloride-laden environment.

\section{(3) Corrosion Area}

Figure 8 shows the time-related changes in the corrosion area of SD345 in contact with Cr-bearing rebars in carbonated concrete. The corrosion area of SD345 increases as the corrosion-accelerating curing proceeds regardless of the type of steel in contact. Also, when compared at the same number of corrosion-accelerating cycles, the corrosion area of SD345 bars in contact with Cr-bearing bars is slightly smaller than that of SD345 in contact with SD345. These results are similar to the above-mentioned results under chloride-laden conditions, and the half-cell potential of SD345 in contact with Cr-bearing steel is slightly less negative than SD345 in contact with SD345 when compared at the same number of cycles of corrosion-accelerating curing. Accordingly, the results of the corrosion area shows that no corrosion-accelerating phenomenon due to galvanic corrosion is observed on normal steel in contact with $\mathrm{Cr}$ bearing steel in a carbonated environment. The corrosion area of SD345 (normal steel) in contact with Cr-bearing steel with a higher $\mathrm{Cr}$ content rather tends to be smaller than that of SD345 in contact with SD345.

\section{(4) Corrosion Loss}

Figure 9 shows the time-related changes in the corrosion loss of SD345 in contact with various Cr-bearing rebars in carbonated concrete. The corrosion loss of SD345 increases as the number of corrosion-accelerating curing cycles increases regardless of the bar type similarly to the results of the corrosion area. Also, the corrosion loss of SD345 in contact with Cr-bearing steel is slightly smaller than that of SD345 in contact with SD345.

According to the above-mentioned results of the half-cell potential, corrosion area, and corrosion loss tests, it is inferred that corrosion of normal steel in contact with $\mathrm{Cr}$ bearing steel in carbonated concrete is not accelerated by galvanic corrosion. As is well known, the intersection of the anodic polarization curve of the less noble steel and the cathodic polarization curve of the more noble steel in contact with each other indicates the corrosion potential and corrosion current. When Cr-bearing steel and SD345 come into contact, the intersection of the cathodic polarization curve of Cr-bearing steel, the more noble steel, and the anodic polarization curve of SD345, the less noble steel, determines the corrosion rate. It follows that the cathodic polarization curve of Cr-bearing steel, which is smaller, similarly to stainless steel, than that of normal steel intersects

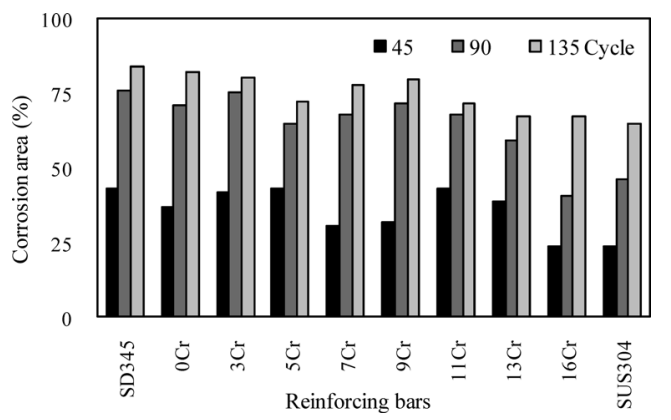

Fig. 8. Corrosion area of SD345 in contact with various types of rebars [carbonation environment].

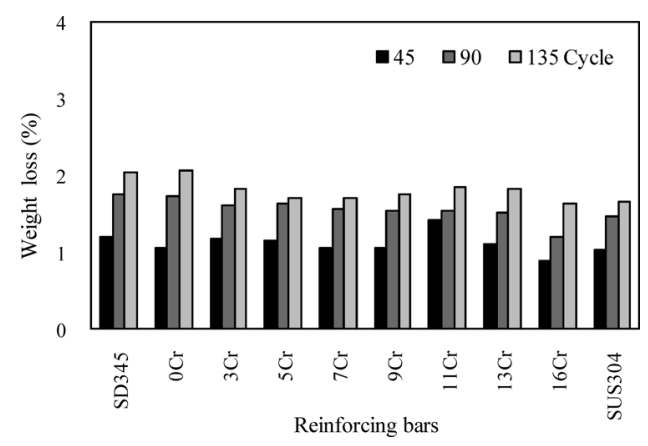

Fig. 9. Corrosion loss of SD345 in contact with various types of rebars [carbonation environment].

with the anodic curve of normal steel at a point at a lower corrosion current than the intersection formed by two normal steels. ${ }^{25,26)}$ Also, other previous studies reported that Cr-bearing bar and normal metal can be combined for use within concrete since difference of electro-chemical potential of Cr-bearing bar and normal metal within concrete is very small. ${ }^{27)}$ This can be the reason for the smaller corrosion of SD345 in contact with Cr-bearing steel than the corrosion of SD345 in contact with SD345.

\section{Summary}

Normal rebars were electrically connected with corrosion-resistant $\mathrm{Cr}$-bearing rebars and embedded in concrete specimens assuming chloride-laden and carbonated environments to investigate if the corrosion acceleration phenomenon due to galvanic corrosion occurs. The half-cell potential, corrosion area, and corrosion loss of SD345 bars in contact with Cr-bearing bars were measured after the specified periods of corrosion-accelerating curing. As a result, the following were found:

(1) No corrosion-accelerating phenomenon due to galvanic corrosion occurred on SD345 rebars in contact with Cr-bearing rebars in concrete with a chloride content of $1.2 \mathrm{~kg} / \mathrm{m}^{3}$.

(2) No corrosion-accelerating phenomenon due to galvanic corrosion occurred on SD345 rebars in contact with Cr-bearing rebars in carbonated concrete.

(3) The corrosion current indicated by the intersection of the cathodic curve of Cr-bearing steel and the anodic curve of normal steel in contact with each other is smaller than that formed by two normal steels in contact with each other, because the cathodic polarization curve of Cr-bearing steel is smaller than that of normal steel. It is therefore in- 
ferred that Cr-bearing rebars can be selectively used for newly built structures only where necessary and can be utilized as a repair material for patching of existing structures.

\section{Acknowledgments}

This work is part of a study supported by JFE Steel Corporation. It is also supported by the Sustainable Building Research Center of Hanyang University, which was supported by the SRC/ERC program of MEST (Grant \# R112005-056-01003-0).

\section{REFERENCES}

1) N. Otsuki, S. Miyazato, N. Diola and H. Suzuki: ACI Mater. J., 97 (2000), 453.

2) K. Kobayashi and T. Miyagawa: Fourth Int. Conf. of Concrete under Severe Conditions of Environment and Loading (Consec04), Vol. 1, ed. by B. H. Oh et al., Seoul National University, Seoul, (2004), 249.

3) C. Q. Li, R. E. Melchers and J. J. Zheng: ACI Mater. J., 103 (2006), 479.

4) Z. T. Park, Y. S. Choi, J. G. Kim and L. Chung: Cem. Conc. Res., 35 (2005). 1814

5) S. Frangini and N. De Cristofaro: Corros. Sci., 45 (2003), 2769.

6) C. M. Abreu, M. J. Cristobal, M. F. Montemor, X. R. Novoa, G. Pena and M. C. Perez: Electrochim. Acta, 47 (2002), 2271.

7) J. M. Miranda, A. Fernandez-Jimenez, J. A. Gonzalez and A. Palomo: Cem. Conc. Res., 35 (2005), 1210.

8) R. D. Hooton and M. P. Titherington: Cem. Conc. Res., 34 (2004), 1561.

9) R. E. Weyers: ACI Mater. J., 95 (1999), 445

10) F. N. Smith and M. Tullmin: Mater. Perform., May (1999), 72.

11) P. C. Borges, O. T. Rincon, E. I. Moreno, A. A. Torres-Acosta, M.
Martinez-Madrid and A. Knudsen: Mater. Perform., October (2002), 50 .

12) R. A. Treece and J. O. Jirsa: ACI Mater. J., 86 (1989), 167.

13) T. Miura, H. Itabashi and I. Iwaki: ACI Mater. J., 94 (1997), 267.

14) S. H. Tae, T. Noguchi and T. Ujiro: ISIJ Int., 46 (2006), 1467.

15) S. H. Tae and T. Ujiro: ISIJ Int., 47 (2007), 715.

16) S. H. Tae, T. Noguchi and T. Ujiro: ISIJ Int., 47 (2007), 146.

17) S. H. Tae and T. Ujiro: ISIJ Int., 47 (2007), 1324.

18) Japan Concrete Institute, Examination Method and Criterion about Corrosion, Corrosion Resistance of a Concrete Construction (Plan), JCI-SC1, Corrosion Evaluation Method of Steel Materials in Concrete, (1987), 1.

19) The Concrete Society, Guidance on the Use of Stainless Steel Reinforcement, Technical Report No. 51, Surrey, (1998).

20) O. Klinghoffer: Corrosion Aspects of Galvanic Coupling between Carbon Steel and Stainless Steel in Concrete, FORCE Institute, Denmark, (1999), 14

21) P. Pedeferri: Behaviour of Stainless Steels in Concrete. Repair and Rehabilitation of Reinforced Structures: the State of the Art, Ed: Silva Araya, W. F. et al., American Society of Civil Engineers, Virginia, (1998), 192

22) ASTM C 876-80, Standard Test Method for Half Cell Potentials of Reinforcing Steel in Concrete, ASTM, Pennsylvania, (1981), 554.

23) J. H. Yoo, Z. T. Park, J. G. Kim and L. Chung: Cem. Conc. Res., 33 (2003), 2057.

24) S. H. Tae, H. S. Lee, T. Noguchi and T. Ujiro: ISIJ Int., 46 (2006), 1086.

25) T. Yamaji: Proc. of the Japan Concrete Institute, ed. by H. Matsushita et al., Vol. 29, Japan Concrete Institute, Tokyo, (2007), 1335.

26) T. Yamaji, T. Aoyama, M. Yamagawa and T. Simizu: Proc. of the JSMS Symposium on Concrete Structures Scenarios, JSMS, Kyoto, (2001), 69.

27) S. Rostam: Mater. Corros., 54 (2003), 369. 